\title{
Biphase Amplifier based Precision Rectifiers using Current Conveyors
}

\author{
Parveen Beg \\ Department of Electronics \\ Engineering, \\ Z. H. College of Engineering \& \\ Technology, \\ Aligarh Muslim University, \\ Aligarh-202002, India
}

\author{
lqbal A. Khan \\ Department of Electrical \\ Engineering, \\ Faculty of Engineering \& \\ Islamic Architecture, \\ Umm Al Qura University, \\ Makka Al Mukarrama, \\ P. Box: 5555, Kingdom of \\ Saudia Arabia
}

\author{
Sudhanshu Maheshwari \\ Department of Electronics \\ Engineering, \\ Z. H. College of Engineering \& \\ Technology, \\ Aligarh Muslim University, \\ Aligarh-202002, India
}

\begin{abstract}
A novel and simple circuit for precision rectifier using second-generation current conveyor (CCII) is presented in this article. The circuit basically uses a CCII-based voltage mode bi-phase amplifier, which has been used as full-wave and halfwave rectifiers. To switch the bi-phase amplifier from noninverting to inverting mode, a MOSFET and a CCII-based comparator has been used. The circuit exhibits precision rectification over a wide range of operation and can also be implemented using commercially available ICs such as the AD844. The proposed circuits have been simulated using CMOS implementation of current conveyor with effective results.
\end{abstract}

\section{General Terms}

Analog Signal Processing, Electronic Circuits

\section{Keywords}

Current conveyors, bi-phase amplifier, precision rectifiers, DVCC

\section{INTRODUCTION}

Precision rectifiers form an important building block in non linear analog processing systems. In such rectifiers, the threshold voltages associated with diodes are overcome and hence enable the rectification at relatively low signal levels required for signal processing applications. With the advent of current conveyors, which offer a number of advantages over other devices, many precision rectifiers using current conveyors have been recently reported in literature [1-16]. However, many of them use a complex circuitry [6-9]. In this paper, novel precision rectifiers using Second-Generation Current Conveyor (CCII) and Differential Voltage Current Conveyor (DVCC) based bi-phase amplifier are presented. The bi-phase mode of the amplifier is controlled with the help of an additional voltage controlled switch and a comparator to achieve half-wave and full-wave rectification. The proposed precision rectifier offer features such as simpler hardware and a wide frequency range of operation. Non-ideal and parasitic study of the proposed circuits is also performed. The circuit proposed is designed and verified using PSPICE.

\section{CIRCUIT DESCRIPTION}

The second-generation current conveyor (CCII) symbol is shown in Fig.1, which is characterized by

$$
V_{X}=V_{Y}, \quad I_{Y}=0 \quad, \quad I_{Z+}=I_{X}
$$

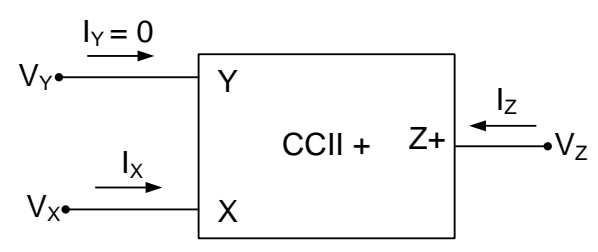

Fig 1: The symbol of CCII

The CMOS implementation of the CCII along with a buffer is given in Fig. 2, while the realized bi-phase amplifier is shown in Fig. 3.

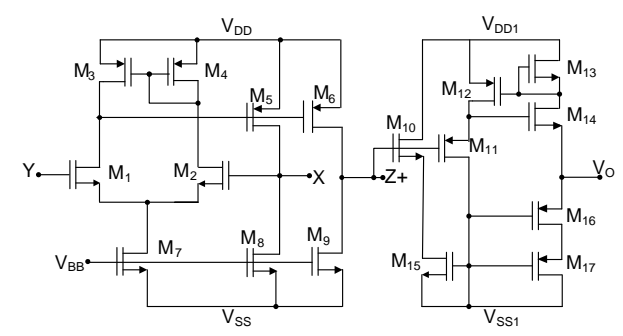

Fig 2: The CMOS structure of the CCII with buffer

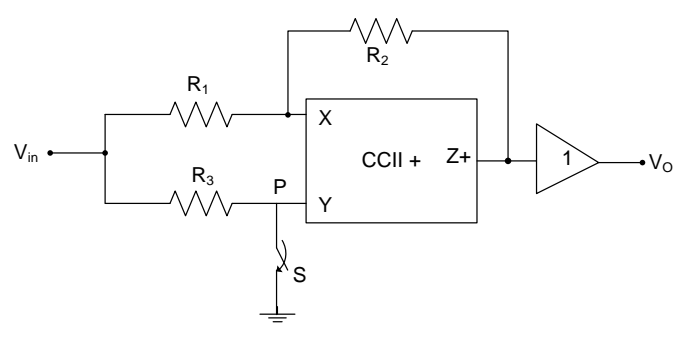

Fig 3: CCII based bi-phase amplifier

The amplifier uses a voltage-controlled switch $S$. When $S$ is open, the output voltage $V_{0}$ can be expressed as:

$$
V_{\mathrm{O}}=V_{\text {in }}
$$

When $S$ is closed, the voltage at node $P$ is zero. Now by selecting $R_{2}=2 R_{l}$ the output voltage becomes:

$$
V_{\mathrm{O}}=-V_{\text {in }}
$$

Thus from equations (2) and (3), it is clear that the circuit of Fig. 2 realizes a bi-phase amplifier. To realize a precision rectifier, the switch $S$ of the bi-phase amplifier has been 
realized with a P-MOS transistor along with CCII+ based non-inverting comparator as shown in Fig. 4.

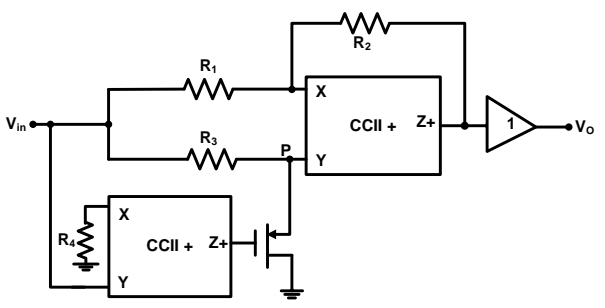

Fig 4: Proposed precision rectifier circuit-I

\subsection{Additional precision rectifier circuit}

The circuit presented in this section is a modified form of the circuit shown in Fig. 3. This modified circuit employs a DVCC-based biphase amplifier. Further, the switch of the biphase amplifier is also realized using a DVCC-based comparator and a NMOS transistor. The symbol of a DVCC with only a $\mathrm{Z}+$ output is shown in Fig. 5 [17], which is characterized by the following port relationship.

$$
V_{X=1}=V_{Y 1}-V_{Y 2}, \quad I_{Y}=0 \quad, \quad I_{Z+}=I_{X}
$$

Fig 5: Symbol of DVCC

The DVCC-based precision rectifier is shown in Fig.6. Here, DVCC (2) is used as a comparator [17]. During the positive half of the cycle, the comparator output is low and the switch is open thus leading to $\mathrm{V}_{0}=\mathrm{V}_{\mathrm{in}}$. During the negative half of the cycle, the comparator output is high; the switch is closed, and thus the bi-phase amplifier behaves in an inverting mode resulting in $\mathrm{V}_{0}=-\mathrm{V}_{\text {in }}$. As a result, full-wave rectification is achieved. The advantage of this circuit over the previous circuit (shown in Fig. 4) is that one passive resistance $R_{4}$ is eliminated and the PMOS transistor is replaced by an NMOS transistor which is suitable for IC fabrication in terms of area.

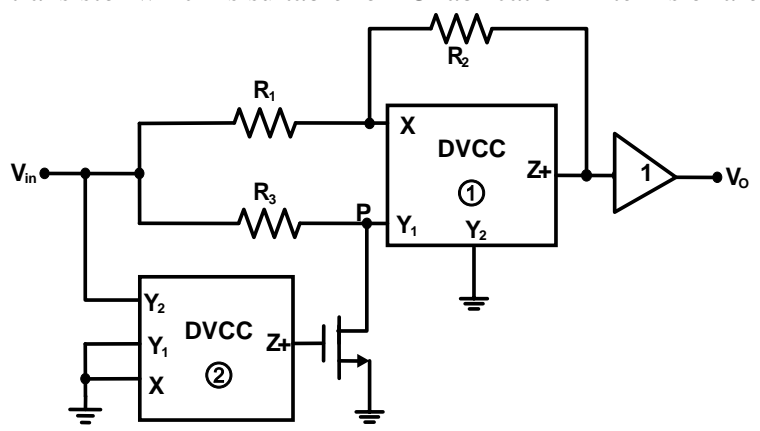

Fig 6: Proposed precision rectifier circuit-II

\section{NON-IDEAL ANALYSIS}

\subsection{Effect of transfer gain}

A non-ideal CCII is characterised by

$$
V_{X}=\beta V_{Y}, \quad I_{Y}=0 \quad, \quad I_{Z+}=\alpha I_{X}
$$

where $\beta$ is the voltage transfer gain from $Y$ to $X$ and $\alpha$ is the current transfer gain from $\mathrm{X}$ to $\mathrm{Z}+$. Re-analysis of the first proposed circuit of Fig. 4 using equation (5) yields the following relation:

During the positive half cycle:

$$
\frac{V_{0, n}}{V_{i}}=\frac{R_{2}}{2 R_{1}}\left[\frac{\beta_{11}+3 \beta_{11} \alpha_{11}-2 \alpha_{1}}{1+\alpha_{1}}\right]
$$

During the negative half cycle:

$$
\frac{V_{0, n}}{V_{i}}=-\frac{R_{2}}{R_{1}}\left(\frac{\alpha_{1}}{1+\alpha_{1}}\right)
$$

Selecting $\mathrm{R}_{2}=2 \mathrm{R}_{1}$, equations (6) and (7) reduce to:

$$
\begin{gathered}
\frac{V_{0, n}}{V_{i}}=\left[\frac{\beta_{11}+3 \beta_{11} \alpha_{11}-2 \alpha_{1}}{1+\alpha_{1}}\right] \\
\frac{V_{0, n}}{V_{i}}=-2\left(\frac{\alpha_{1}}{1+\alpha_{1}}\right)
\end{gathered}
$$

It is to be further noted that equations (8) and (9) reduce to equations (2) and (3) respectively for $\alpha_{1}=\beta_{11}=1$.

\subsection{Effect of Parasitics}

A CCII is characterised by the following parasitic port impedances: The parasitics are $\mathrm{R}_{\mathrm{X}}, \mathrm{R}_{\mathrm{Y}} / / \mathrm{C}_{\mathrm{Y}}$ and $\mathrm{R}_{\mathrm{Z}} / / \mathrm{C}_{\mathrm{Z}}$ for $\mathrm{X}$ , $\mathrm{Y}-$ and $\mathrm{Z}$ ports respectively. Considering the $\mathrm{X}$ - and $\mathrm{Y}$ terminal parasitics, the output voltage during the positive half cycle can be expressed as:

$$
\frac{V_{0}^{\prime}}{V_{i}}=-\frac{R_{2}-R_{X}}{\left(2 R_{1}+R_{X}\right)} \frac{\left[s+\frac{1}{C_{Y} R_{Y}}-\frac{\left(2 R_{1}+R_{X}\right)}{C_{Y} R_{3}\left(R_{2}-R_{X}\right)}\right]}{s+\frac{R_{3}+R_{Y}}{C_{Y} R_{3} R_{Y}}}
$$

For a typical design $R_{3} \ll R_{Y}$ thus $\mathrm{R}_{3} / / \mathrm{R}_{\mathrm{Y}} \simeq \mathrm{R}_{3}$. By selecting $R_{2}=2 R_{l}$, equation (10) reduces to:

$$
\frac{V_{0}^{\prime}}{V_{i}}=-\frac{\left(2 R_{1}-R_{X}\right)}{\left(2 R_{1}+R_{X}\right)} \frac{\left[s+\frac{1}{C_{Y} R_{Y}}-\frac{\left(2 R_{1}+R_{X}\right)}{C_{Y} R_{3}\left(2 R_{1}-R_{X}\right)}\right]}{s+\frac{1}{C_{Y} R_{3}}}
$$

During the negative half of the cycle the output voltage can be expressed as:

$$
\frac{V_{0}^{\prime}}{V_{i}}=-\frac{\left(2 R_{1}-R_{X}\right)}{\left(2 R_{1}+R_{X}\right)} \frac{\left[s+\frac{1}{C_{Y} r_{o n}}-\frac{\left(2 R_{1}+R_{X}\right)}{C_{Y} R_{3}\left(R_{2}-R_{X}\right)}\right]}{s+\frac{R_{3}+r_{o n}}{C_{Y} R_{3} r_{o n}}}
$$

where $r_{o n}$ is the ON resistance of MOSFET.

Again, in equation (12) $r_{o n} \ll<R_{3}$ thus $r_{o n} / / \mathrm{R}_{3} \simeq r_{o n}$. By selecting $R_{2}=2 R_{1}$, equation (12) reduces to:

$$
\frac{V_{0}^{\prime}}{V_{i}}=-\frac{\left(2 R_{1}-R_{X}\right)}{\left(2 R_{1}+R_{X}\right)} \frac{\left[s+\frac{1}{C_{Y} r_{o n}}-\frac{\left(2 R_{1}+R_{X}\right)}{C_{Y} R_{3}\left(2 R_{1}-R_{X}\right)}\right]}{s+\frac{1}{C_{Y} r_{o n}}}
$$


Closer inspection of equations (11) and (13) for a typical design shows that the gain of the rectified output is not affected. The pole and zero introduced due to parasitics are found to be symmetrical and approximately equal in magnitude, thus they may be the cause for certain phase errors. It is also to be noted that for open-switch as well as for closed-switch conditions (equation (11) and (13)), the path from port $\mathrm{Y}$ to ground will contain $\mathrm{R}_{\mathrm{Y}}$ or $\mathrm{R}_{\mathrm{Y}} / \mathrm{r}_{\mathrm{ON}}$ respectively. Therefore both equations (11) and (13) show a 'minus' sign.

\section{DESIGN AND VERIFICATION}

To verify the proposed theory, the precision rectifier of Fig. 4 is designed and simulated using PSPICE. The model parameters for the CMOS CCII are taken from MIETEC 0.5 $\mu \mathrm{m}$ CMOS process [18]. The PMOS switch is implemented with the $W / L$ ratio as $7 \mu \mathrm{m} / 0.35 \mu \mathrm{m}$. For a bi-phase amplifier, selecting $R_{1}=1 \mathrm{~K} \Omega$ leads to $R_{2}=2 \mathrm{~K} \Omega . R_{3}$ and $R_{4}$ are selected as $150 \mathrm{~K} \Omega$ and $400 \Omega$ respectively. The supply voltages are taken as $V_{D D}=-V_{S S}=2.5 \mathrm{~V}$ and $V_{B B}=-1.96 \mathrm{~V}$. The MOS transistors aspect ratios for the CMOS CCII are given in Table 1. The resulting DC transfer characteristics of the proposed precision rectifier are shown in Fig.7. Its performance is also verified with a sinusoidal input of $20 \mathrm{mV}$ peaks at $10 \mathrm{KHz}$, $100 \mathrm{KHz}$ and $1 \mathrm{MHz}$, the results of which are depicted in Fig.8-10.

The proposed circuit of Fig. 6 is designed with $R_{l}=$ $2 \mathrm{~K} \Omega, R_{2}=4 \mathrm{~K} \Omega$ and $R_{3}=40 \mathrm{~K} \Omega$. The supply voltages are kept as before. The NMOS transistor aspect ratio is $10 \mu \mathrm{m} / 0.35$ $\mu \mathrm{m}$. The full-wave rectified output at $20 \mathrm{mV}$ peaks and at 1 $\mathrm{MHz}$ are shown in Fig. 11.

The distortions visible during the clock switching edge at increasing frequencies are mainly due to the switching limitation of the transistor. These may be reduced by employing high frequency transistors.

Table 1. Dimensions of the transistors used in CCII

\begin{tabular}{ccc}
\hline Transistor & $\boldsymbol{W}(\boldsymbol{\mu} \mathbf{m})$ & $\boldsymbol{L}(\boldsymbol{\mu m})$ \\
\hline $\mathrm{M}_{1}, \mathrm{M}_{2}$ & 0.8 & 0.5 \\
$\mathrm{M}_{3}, \mathrm{M}_{4}$ & 4 & 0.5 \\
$\mathrm{M}_{5}, \mathrm{M}_{6}$ & 10 & 0.5 \\
$\mathrm{M}_{7}$ & 14.4 & 0.5 \\
$\mathrm{M}_{8}, \mathrm{M}_{9}$ & 45 & 0.5 \\
\hline
\end{tabular}

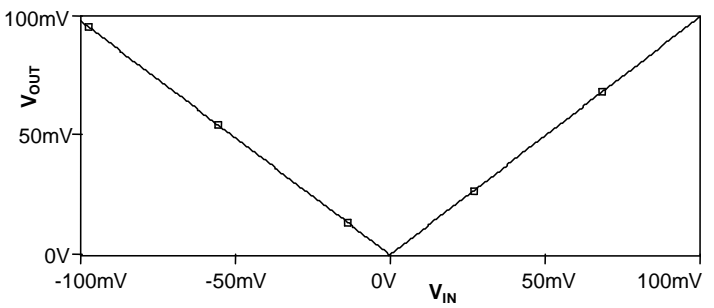

Fig 7: DC transfer characteristics of the precision rectifier
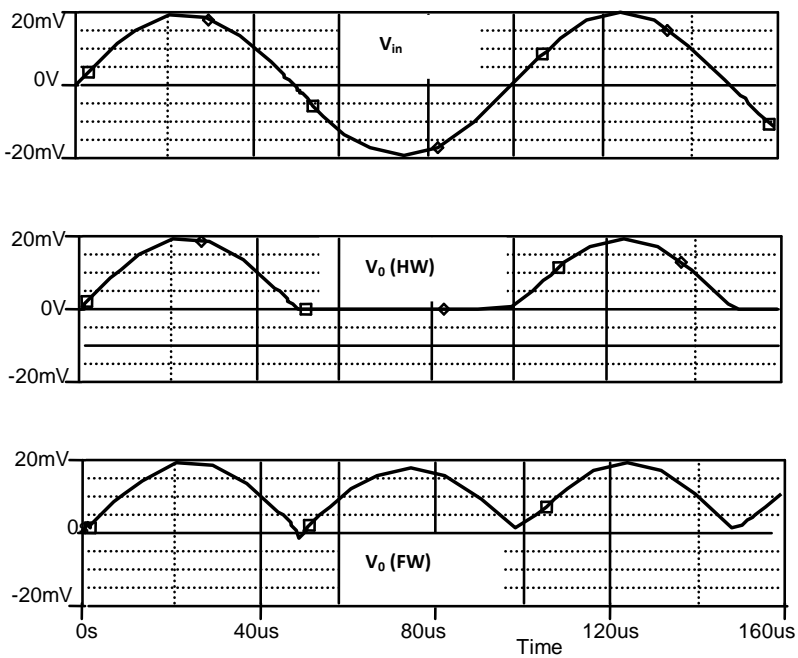

Fig 8: Input and output waveforms at $10 \mathrm{KHz}$ of the of the precision rectifier shown in Fig 4.
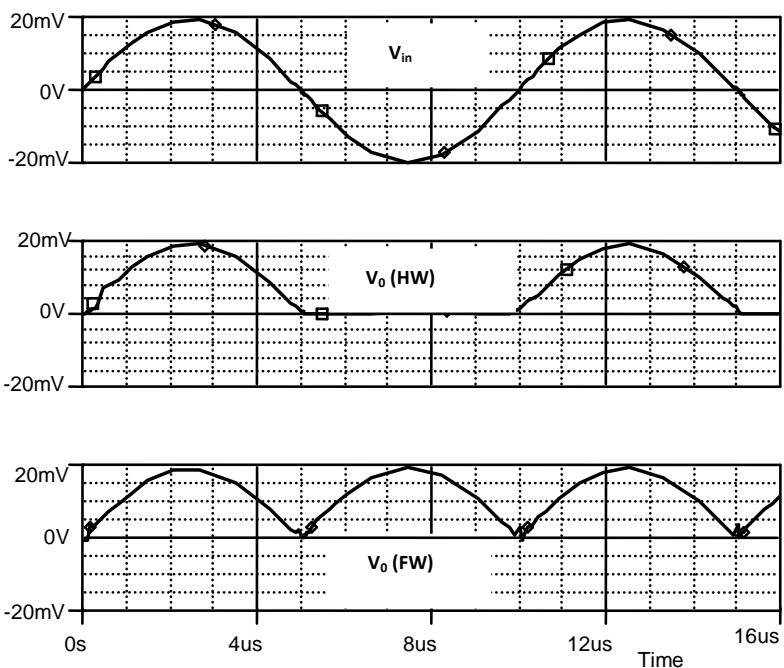

Fig 9: Input and output waveforms at $100 \mathrm{KHz}$ of the precision rectifier shown in Fig 4.
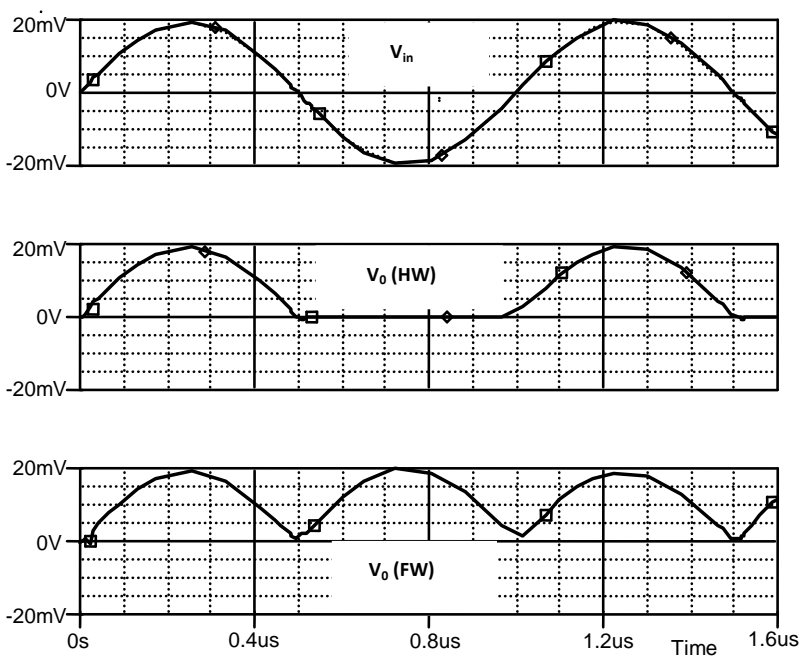

Fig 10: Input and output waveforms at $1 \mathrm{MHz}$ of the precision rectifier shown in Fig 4. 


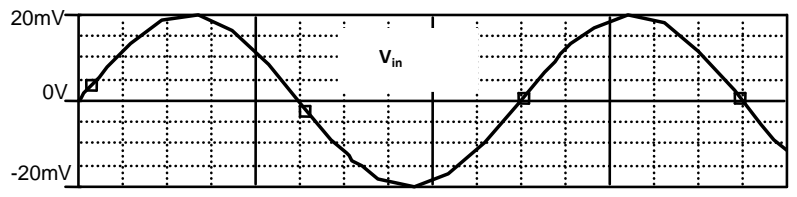

口 $\mathrm{V}(1)$

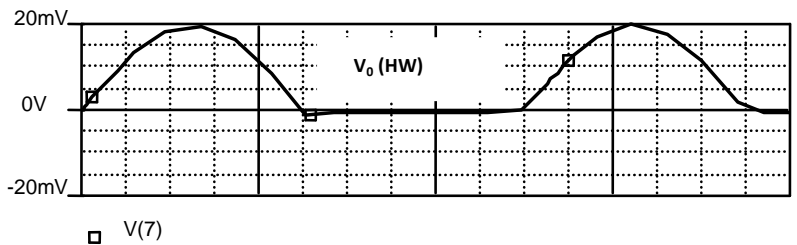

口 $V(7)$

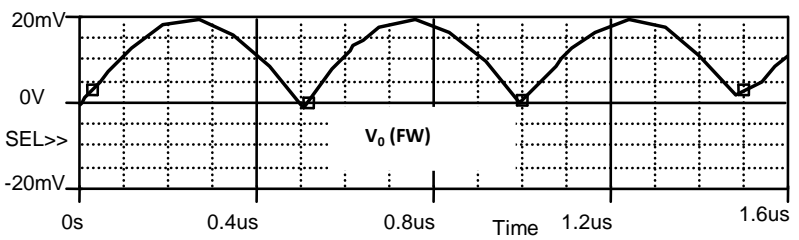

Fig 11: Input and output waveforms at $1 \mathrm{MHz}$ of the precision rectifier shown in Fig. 6

\section{COMPARATIVE STUDY}

The circuits proposed in this work were compared to similar circuits reported in literature. The different parameters used for comparison were:

$\begin{aligned} \text { i. } & \text { Type of active building blocks used } \\ \text { ii. } & \text { Number of diodes } \\ \text { iii. } & \text { Number of resistors } \\ \text { iv. } & \text { Half-wave and/or full wave capability } \\ \text { v. } & \text { Operating frequency } \\ \text { vi. } & \text { Signal (voltage or current) amplitude range }\end{aligned}$

Table 2. Comparison of proposed and existing circuits

\begin{tabular}{|c|c|c|c|c|c|c|}
\hline \multirow{2}{*}{ Reference No. } & \multicolumn{6}{|c|}{ Feature } \\
\hline & (i) & (ii) & (iii) & (iv) & (v) & (vi) \\
\hline$[2]$ & 2 CCII, 2OPAMP & 4 & 2 & $\mathrm{~N} / \mathrm{Y}$ & $100 \mathrm{KHz}$ & $\pm 500 \mathrm{mV}$ \\
\hline [4] & 1 FDIO-OTA & 4 & 1 & $\mathrm{Y} / \mathrm{Y}$ & $500 \mathrm{MHz}$ & $\pm 500 \mathrm{mV}$ \\
\hline [6] & $2 \mathrm{CCII}$ & 4 & 2 & - & $30 \mathrm{MHz}$ & - \\
\hline [7] & $2 \mathrm{CCII}$ & 4 & 2 & $\mathrm{~N} / \mathrm{Y}$ & $100 \mathrm{KHz}$ & $\pm 100 \mathrm{mV}$ \\
\hline [8] & 1 CCII, 2 OPAMP & 2 & 3 & $\mathrm{~N} / \mathrm{Y}$ & $100 \mathrm{MHz}$ & $\pm 1 \mathrm{~V}$ \\
\hline [9] & CCII- & - & 1 & $\mathrm{Y} / \mathrm{N}$ & $100 \mathrm{MHz}$ & $\pm 25 \mathrm{mV}$ \\
\hline [10] & $1 \mathrm{CCII}, 2 \mathrm{MOS}$ & - & 1 or 0 & $\mathrm{Y} / \mathrm{Y}$ & $100 \mathrm{KHz}$ & $\pm 10 \mathrm{mV}$ \\
\hline [11] & CDTA & 4 & 2 & $\mathrm{~N} / \mathrm{Y}$ & $5 \mathrm{MHz}$ & $\pm 50 \mu \mathrm{A}$ \\
\hline [12] & 2 CCII, 2 MOS & - & 2 & $\mathrm{~N} / \mathrm{Y}$ & $20 \mathrm{KHz}$ & $\pm 20 \mathrm{mV}$ \\
\hline [13] & 3 CCCII & - & - & $\mathrm{N} / \mathrm{Y}$ & $100 \mathrm{KHz}$ & - \\
\hline [14] & $3 \mathrm{CCII}$ & - & - & $\mathrm{N} / \mathrm{Y}$ & $1 \mathrm{MHz}$ & $\pm 80 \mu \mathrm{A}$ \\
\hline [15] & 2 CCII, 3 MOS & - & - & - & $250 \mathrm{KHz}$ & $\pm 50 \mathrm{mV}$ \\
\hline [16] & DXCCII, 3MOS & - & - & $\mathrm{N} / \mathrm{Y}$ & $1 \mathrm{MHz}$ & $\pm 150 \mathrm{mV}$ \\
\hline Proposed (Fig.4) & 2 CCII, 1 MOS & - & 4 & $\mathrm{Y} / \mathrm{Y}$ & $1 \mathrm{MHz}$ & $\pm 20 \mathrm{mV}$ \\
\hline Proposed (Fig.6) & $2 \mathrm{DVCC}, 1 \mathrm{MOS}$ & - & 3 & $\mathrm{Y} / \mathrm{Y}$ & $1 \mathrm{MHZ}$ & $\pm 20 \mathrm{mV}$ \\
\hline
\end{tabular}

\section{REFERENCES}

[1] Wilson, B. 1990. Recent development in current conveyors and current mode circuits. IEE Proc. G, 132 (2), 63-67.

[2] Gift, S. J. G. 2002. An improved precision full-wave rectifier. International Journal of Electronics, 89(3), 259265.
The results are depicted in Table 2. It may be noted that most of the available circuits are based on two current conveyors. There are some works which benefit from using only a single current conveyor or OTA $[4,9,10,16]$. However one of these [9] exhibits only half-wave rectification. As far as the frequency range is concerned, the circuit proposed by [9] with half wave capability is quite attractive. Similarly the work proposed by [6] also exhibits good frequency performance but employs a number of diodes.

The circuits proposed by $[10,12]$ exhibit good precision. However the operating frequency for the latter is limited as compared to the former, though it may not be entirely fair to compare these circuits since they fall in the class of tunable precision rectifiers. However, as can be seen, the circuits proposed in this work benefit from a good precision, half wave as well as full-wave operation and a moderate to good operating frequency. Moreover, the new proposed circuits are a novel addition to the already vast literature on the subject

\section{CONCLUSION}

In this work, a novel precision rectifier using second generation current conveyor is realized. The realized precision rectifier uses a CCII-based voltage mode bi-phase amplifier. To switch the bi-phase amplifier from non-inverting to inverting mode, a MOSFET switch and a CCII based comparator has been used. A DVCC based precision rectifier circuit is further introduced. Non-ideal and parasitic study is also given. The rectifier was designed and verified using PSPICE simulation. The results prove that the circuit achieves half-wave as well as full-wave precision rectification The simulated precision rectifier also exhibits a wide frequency range of operation and uses simple hardware. Improving the performance and high precision capability of the circuit is an area open for further research. 
[6] Toumazou, C., Lidgey, F. J., and Chattong, S. 1994. High frequency current conveyor precision full-wave rectifier. Electronics Letters, 30, 745-756.

[7] Monpapassorn, A., Dejhan, K. and Cheevasuvit, F. 2001. A full-wave rectifier using a current conveyor and current mirrors. International Journal of Electronics, 88, 751-758.

[8] Gift, S. J. G. 2000. A high-performance full-wave rectifier circuit. International Journal of Electronics, 89, 467-476.

[9] Kumngern, M. and Dejhan. K. (2007). High frequency, high precision CMOS half-wave rectifier. In Proceedings of the The ECTI International Conference, Thailand, 1-4.

[10] Maheshwari, S. 2007. Current controlled precision rectifier circuits. Journal of Circuits Systems and Computers. 16(1), 129-138

[11] Biolek, D., Hancioglu, E., and Keskin Umit, A. 2008. High-performance current differencing transconductance amplifier and its application in precision current-mode rectification. International Journal of Electronics and Communications, 62, 92-96.

[12] Maheshwari, S. and Khan, I. A. 2005. An integrable precision rectifier with current controlled output. Journal of Active and Passive Electronic Devices, 1, 172-182.

[13] Anuntahirunrat. K., Tangsrirat, W., Riewruja, V., and Surakampontorn, W. 2000. Sinusoidal frequency doubler and full-wave rectifier using translinear current controlled conveyors. In Proceedings of Conference on Circuits and Systems (IEEE APCCAS), China. 166-169.

[14] Siripruchyanun, M. and Jaikla, W. 2006. A novel precision current-mode full-wave rectifier and class B push-pull current amplifier using BiCMOS currentcontrolled current conveyors. The Journal of King Mongkut's University of Technology, North Bangkok. 16(1), 1-6.

[15] Yuce, E., Minaei, S., and Cicekoglu, O. 2006. Full-wave rectifier realization using only two CCIIs and NMOS transistors. International Journal of Electronics, 93(8), 533-541.

[16] Minaei, S. and Yuce, E. 2008. A new full-wave rectifier circuit employing single dual-X current conveyor. International Journal of Electronics, 95(8), 777-784.

[17] Maheshwari, S. 2008. A canonical voltage-controlled VM-APS with a grounded capacitors. Circuit System Signal Processing, 27, 123-132.

[18] Minaei, S., Ibrahim, A. Muhammed and Kuntman, H. 2003. DVCC based current-mode first order all-pass filter and its application. In Proceedings of The $10^{\text {th }}$ IEEE International Conference on Electronics Circuits and Systems, Turkey, 276-279. 